\title{
Review of telemedicine projects in Taiwan
}

\author{
Heng-Shuen Chen ${ }^{\mathrm{a}, \mathrm{b}, *}$, Fei-Ran Guo ${ }^{\mathrm{a}}$, Ching-Yu Chen ${ }^{\mathrm{a}}$, Jye-Horng Chen ${ }^{\mathrm{b}, 1}$, \\ Te-Son Kuo ${ }^{b}$
}

\author{
a Department of Medical Informatics \& Department of Family Medicine, Section 1, 1 Jen-Ai Road, Taipei 100, Taiwan \\ ${ }^{\mathrm{b}}$ Institute of Electrical Engineering, National Taiwan University, Section 4, 1 Roosevelt Road, Taipei 100, Taiwan
}

\begin{abstract}
Taiwan is a heavily populated country, with a small land area and many mountains and isolated islands. Because medical resources are unequally distributed, high quality accessible medical care is a major problem in rural areas. Medical personnel are unwilling to practice in rural areas because of fear of isolation from peers and lack of continuing medical education (CME) in those areas. Telemedicine provides a timeless and spaceless measure for teleconsultation and education. The development of telemedicine in Taiwan began under the National Information Infrastructure (NII) Project. Distance education and teleconsultation were the first experimental projects during the initiation research stage. The cost and effectiveness of the hardware and network bandwidth were evaluated. In the promotion research stage, applications in different medical disciplines were tested to promote multipoint videoconference, electronic journals and VOD. Investigation of user satisfaction put on more emphasis on improving application functions. In 1998, a new Cyber Medical Center (CMC) international collaboration project was begun, integrating technologies of multimedia, networking, database management, and the World Wide Web. The aim of the CMC is to create a multimedia network system for the management of electronic patient records, teleconsultation, online continuing medical education, and information services on the web. A Taiwan mirror site of Virtual Hospital and two international telemedicine trials through Next Generation Internet (NGI) were done at the end of 1998. In the future, telemedicine systems in Taiwan are expected to combine the Internet and broadband CATV, ADSL, and DBS networking to connect clinics, hospitals, insurance organizations, and public health administrations; and, finally, to extend to every household. (C) 2001 Elsevier Science Ireland Ltd. All rights reserved.
\end{abstract}

Keywords: Telemedicine; Taiwan; Teleconsultation; Distance education; Primary care

* Corresponding author. Tel.: + 886-2-2312-3456, ext 8749; fax: $+886-2-2393-3031$.

E-mail addresses: chenhs@med.mc.ntu.edu.tw (H.-S. Chen), chen@me.ee.ntu.edu.tw (J.-H. Chen).

${ }^{1}$ Also corresponding author. Tel.: + 886-2-3633174, ext 311; fax: + 886-2-23659043.

\section{Introduction}

Taiwan is a heavily populated country with 22 million people living on a major island of $36000 \mathrm{~km}^{2}$ surrounded by several small isolated islands. Most of the population is concentrated in several metropolitan areas on the 
west coast [1]. On average there is approximately one physician per 800 people in Taiwan. However, most of the medical resources are unequally distributed in several big cities. The largest medical center sometimes treats over 10000 outpatients a day, and the number of inpatients is nearly 3000. The top 10 medical centers consumed one-fourth of the national health expenditure. In these medical centers more money is spent on the outpatient service than the inpatient service. This is unreasonable because a hospital is designed for inpatient service. On average approximately twice as much should be spent on inpatients as outpatients [2]. The reasons for the over-expansion of outpatient service is the emphasis on subspecialty in the medical community, and the public's belief that specialists in medical centers provide the best healthcare. Another factor was the failure of the National Health Insurance system to establish a referral system when it began in 1995 [3]. Because people were free to choose any health service they wanted, primary healthcare was not emphasized, and consulting a family physician was not encouraged. Therefore, qualitative and accessible medical service became a major problem in rural areas.

\subsection{Problems of the primary care in rural areas}

In Taiwan, three-fourths of the land area is mountainous and there are several small isolated islands around the major island. In these rural areas medical resources are underdistributed. According to a government survey, at the end of 1998 medical personnel manpower in mountainous and isolated islands was significantly lower. In the mountainous areas, there are only one-fourth the number of physicians, half of the nurses, and one-third of the medical technicians of the national average. There is a shortage of other medical personnel also. There are only oneninth the dentists, one-tenth the pharmacists of the national average, and there are no nutritionists, physical therapists, occupational therapists or radiology technicians practicing in mountainous area. Isolated islands fare a little better. There are 30\% less physicians, and approximately half of other medical personnel on average. [4]

There are two reasons why medical personnel are unwilling to practice in rural areas. First, they are afraid of isolation from their peers. Second, they lack the chance to receive continuing medical education (CME) in a rural environment. Practicing medicine in a rural area is a challenge. One must face and solve problems by oneself because of the difficulties of distance and resources [5]. After practicing for years, one's medical knowledge becomes outdated. Although experience and wisdom grow, most of the knowledge learned in the medical school might well be forgotten $[6,7]$. In such circumstances, continuing medical education and communication with peers through consultation and referral become important ways to stay up to date. However, it is very difficult for a busy practitioner to leave his job and travel some distance to attend CME lectures and conference [8].

\subsection{Importance of telemedicine}

Telemedicine can be broadly defined as the transfer of electronic medical data from one location to another. This transfer of medical data may utilize a variety of telecommunications technologies, including ordinary telephone lines, ISDN, fractional to full T1, ATM, the Internet, intranet, and satellites $[9,10]$. Telemedicine is utilized by healthcare providers in a growing number of medical specialties and home healthcare $[11,12]$. 
Why do we need telemedicine in Taiwan? (1) Medical resources in rural areas are poorly distributed; (2) the quality of consultation and referral in the rural areas needs to be improved; (3) peer communication among healthcare providers in rural areas, hospitals, and medical centers is difficult; (4) we need to provide continuing medical education online; and (5) for elderly, handicapped, and terminal ill patients, we need a convenient way to provide special healthcare at home [13].

Because of the unequal distribution of medical resources, medical centers, community hospitals and primary care units need an interface for transferring medical information among one another to improve the quality of healthcare in isolated areas. Physicians in remote areas also need a convenient way to receive continuing medical education. Telemedicine provides a timeless and spaceless measure for teleconsultation and continuing medical education [14]. The network established among primary healthcare providers, community hospitals, and medical centers not only improves the quality of primary healthcare in rural areas, but also provides on-the-job training, and interactive communication among different specialties. On the other hand, Taiwan has become an aging country. Those over 65 years old are now $8.2 \%$ of the population [15]. Three chronic diseases, cancer, cerebrovascular disease and cardiac disorders are the top three causes of death. Cancer causes one-fourth of all deaths, therefore, palliative home care for terminal illness has become a major burden for families. In addition, the welfare of the elderly and handicapped is being given more emphasis. Therefore modern information technology to provide home telecare has also become a trend in telemedicine [16-19].

\section{Development of telemedicine in Taiwan}

\subsection{National Information Infrastructure}

The development of telemedicine in Taiwan began under the National Information Infrastructure (NII) project. NII was first initiated by the US government in 1993 and immediately caught the attention of other countries. In Taiwan, the NII Steering Committee is responsible for NII development. Organized among all the ministries, commissions and councils under the Executive Yuan, the NII Steering Committee was installed in August 1994. Significant progress in NII development has been made in the past 5 years. In applications development, experimental projects, such as distance education, teleconsultation, video-on-demand (VOD), and electronic library were launched and are progressing smoothly [20]. Among these projects, distance education and teleconsultation are closely related to telemedicine. The goal of NII is to expand the information superhighway to every household, office, factory and school. NII tries to provide an accessible and affordable information network for every citizen in Taiwan. In July 1999 over 4 million people had Internet access with Taiwan ranked ninth in the world [21]. Ninety-six percent of schools, $35 \%$ of homes and $53.7 \%$ of enterprises, have installed the Internet [22]. Taiwan also ranks seventh in the world in terms of the number of hosts connected to the Internet, with the number reaching 676000 . In the Asia-Pacific region, only Japan and Australia are ranked higher [23].

\subsection{Stages of telemedicine in Taiwan}

The vision of telemedicine in Taiwan is to create an environment, which will facilitate a telemedicine network system in the most effi- 
cient and effective way, as well as to provide the telemedicine services throughout the whole country. This vision can be realized through careful planning, countrywide collaboration and rational implementation and development of telemedicine applications. Therefore the implementation of the telemedicine network in Taiwan can be planned as three stages which include initiation research (1994-1996), promotion research (1997-1999) and implementation (starts in 2000) (Table 1) [24].

During the initiation research stage, different network platforms with different bandwidths were tested to evaluate cost and effectiveness [25]. The government funded distance education and teleconsultation experimental projects under the NII program were tested among national universities and medical centers [26].

We are now in the last year of the promotion research stage, in which the teleconsultation system has been applied in more than 10 medical subspecialties. For continuing medi-

Table 1

The three stages of telemedicine in Taiwan

Initiation research stage (1994-1996)

Distance education experimental project

Broadband ATM DS3 videoconference

Narrowband ISDN $128 \mathrm{~K}$ desktop

videoconference

ISDN $384 \mathrm{~K}$ room based videoconference

Teleconsultation experimental project

ATM DS1 teleconsultation

ISDN $768 \mathrm{~K}+768 \mathrm{~K}$ teleconsultation

Promotion research stage (1997-1999)

Family Medicine Tele-course CME:

videoconference

Multi-center Palliative Medicine Teleconference

Multi-point videoconference

Web-based forum and multimedia case library

Web-based CME network

Virtual classroom

Electronic journal

Implementation stage (starts in 2000) cal education, we launched the delivery of tele-courses to community hospitals via a videoconferencing system and preliminary Internet continuing medical education network in the forms of web-based electronic journal and virtual classroom for the Formosan Medical Association and the Taiwan Association of Family Medicine [27].

Starting in 2000, broadband cable television (CATV) network, asymmetric digital subscriber line (ADSL), and direct broadcast satellite (DBS) communications will be more common. The applications of telemedicine will mature and be ready for marketing. Through the broadband network of the national information infrastructure, telemedicine services will gradually spread nationwide.

\section{Telemedicine projects in Taiwan}

\subsection{Initiation research stage}

\subsubsection{Distance education experimental project}

The distance education project was created to provide interactive learning for people of any background through a telecommunication network, thereby removing the barriers of time and space. Basically distance education can be divided into synchronous and asynchronous modes. The synchronous mode provides face-to-face teaching and learning in real time between teachers and students [28]. The asynchronous mode provides access to course materials and interaction among teachers and students on the network at a time convenient for the student [29-32]. The synchronous mode works as a videoconference. It could be point-to-point or multipoint using a multi-point control unit (MCU) to handle the broadcast and interaction among three or more sites. The network can 


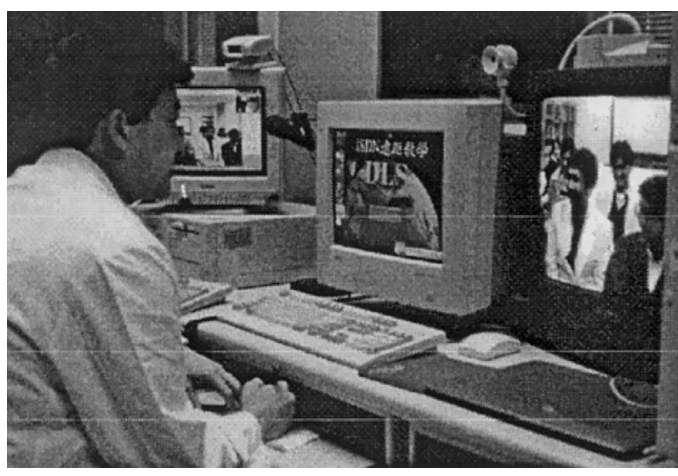

Fig. 1. $128 \mathrm{~K}$ ISDN desktop PC videoconferencing.

be a broadband network such as an Asynchronous Transfer Mode (ATM) network or a narrow band network such as an Integrated Service Digital Network (ISDN) line. The asynchronous mode works as a virtual classroom by using e-mail, bulletin board systems (BBS), newsgroup forums, and archive video lectures to establish a learning environment on the network [33,34]. A good distance education system should fulfill four elements: (1) a widespread network infrastructure capable of multimedia transmission; (2) compatibility with international standards in hardware and software; (3) an interactive function between teacher and student; and (4) a user-friendly interface [35]. The National Taiwan University College of Medicine (NTUCM) used a broadband ATM DS3 network to broadcast medical general education lectures to two other universities for non-medical background students. It was among the first courses opened in the NII distance education experimental project [36,37]. Later another distance education project using a narrowband $128 \mathrm{~K}$ ISDN line and desktop PC videoconferencing was applied to community medicine training for 5th year medical students at NTUCM (Fig. 1) [38]. Both projects were successful and became regular courses at NTUCM. After a 2-year experiment, a tradeoff was made between cost and effec- tiveness. The equipment was standardized to a room-based videoconferencing system connected with three ISDN lines equivalent to $384 \mathrm{~K}$ bandwidth (Fig. 2) [39,40].

\subsubsection{Teleconsultation experimental project}

The NII teleconsultation experimental project combines the knowledge of information technologists and medical specialists to provide medical care by remote consultation for rural and remote isolated islands. It provides medical information in real time between general practitioners in rural areas and specialists in medical centers. It removes barriers and helps decision making in diagnosis and treatment in primary healthcare. As in distance education, teleconsultation can be divided into synchronous and asynchronous consultations. Synchronous consultation uses a high quality videoconferencing system to provide real-time interaction between the primary care physician and the specialist. If the specialist needs to see the patient, he can interview and inspect the patient through the videoconferencing system. In some cases the specialist can perform a physical examination on the patient with the help of a primary care physician or other medical personnel. Auscultation is done by a remote electronic stethoscope [41]. An imaging examination such as ultrasound connected to video input can also

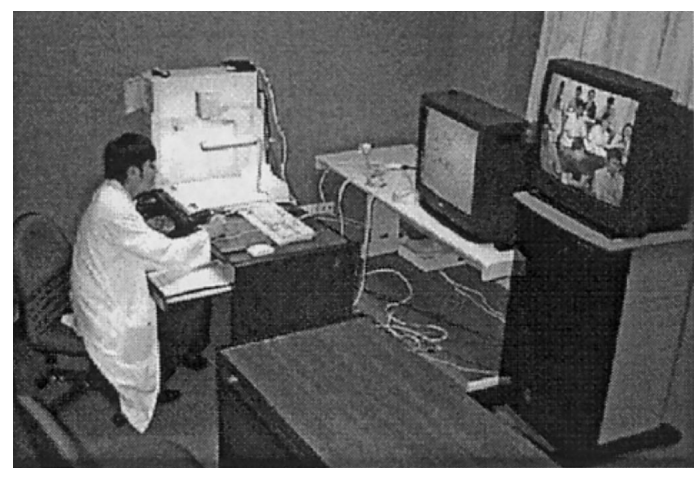

Fig. 2. $384 \mathrm{~K}$ ISDN room-based videoconferencing. 


\section{台大榢院家庭整學科}

\section{金山衛生所}

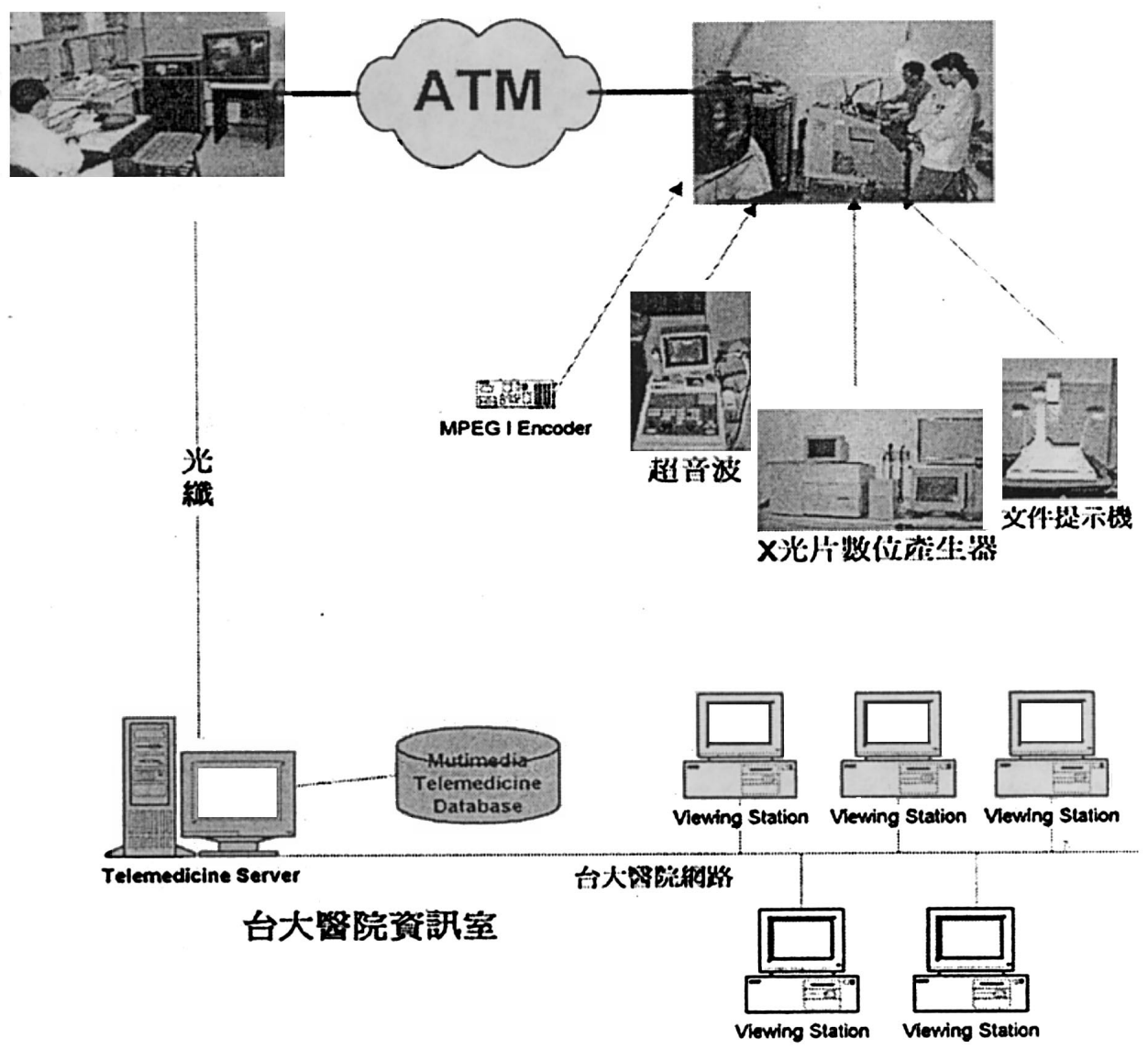

Fig. 3. ATM DS1 teleconsultation network between NTUH and Chinshan health station.

be done remotely. Asynchronous teleconsultation is most frequently used in teleradiology to transmit digitized X-ray film or other digital images such as computer tomography (CT) [42-45]. In 1995 the Department of Health began to fund three NII teleconsultation projects. National Taiwan University Hospital (NTUH) was connected to the Chinshan health station, a primary care unit in a rural area in Taipei County (Fig. 3) [46-50].

Two other medical centers, Veterans Gen- eral Hospital Taipei (VGHTPE) and National Cheng Kung University Hospital (NCKUH) were connected to the community hospitals of two isolated islands, Kin-Men and Peng-Hu [51], respectively. In 1996, another medical center, Tri-Service General Hospital (TSGH), was also connected to another island community hospital in Ma-Tsu (Fig. 4). All of the teleconsultation systems provide both synchronous and asynchronous functions and use a 1.544-Mbps T1 line or 12 ISDN lines equivalent to a T1 bandwidth. 


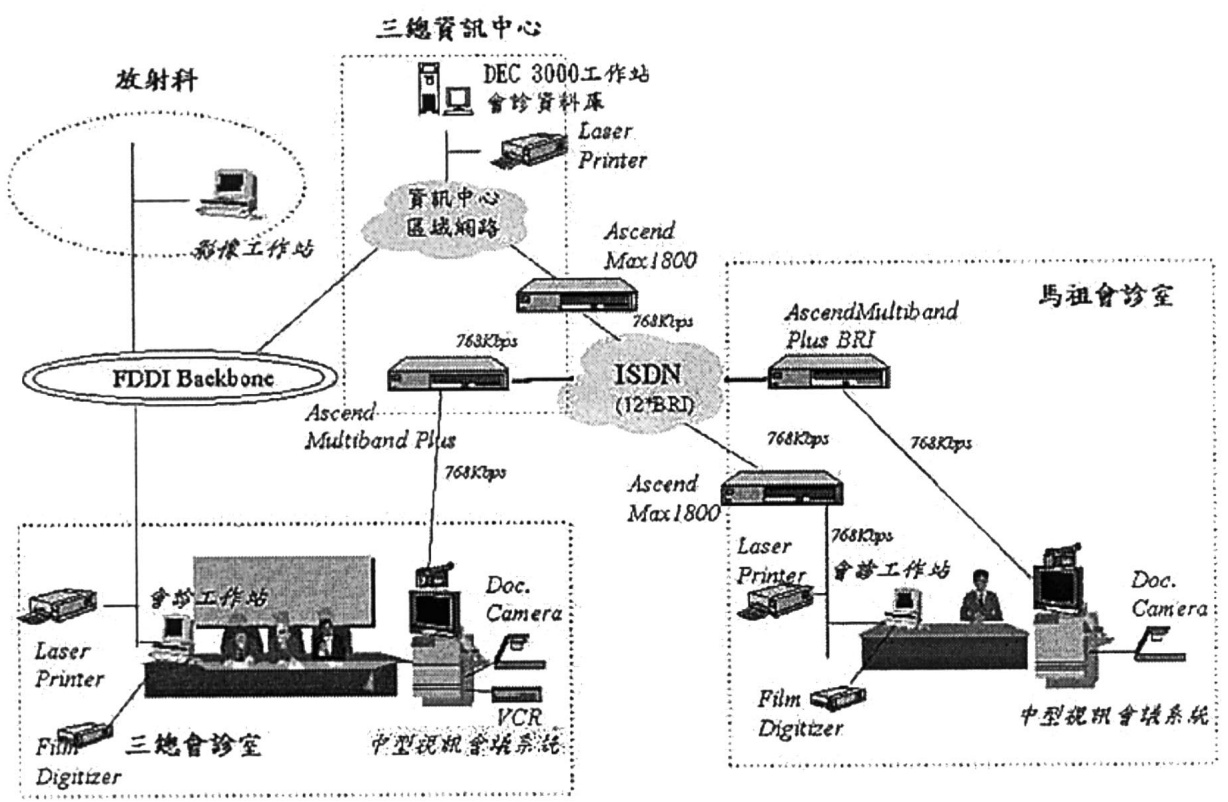

Fig. 4. ISDN teleconsultation network between TSGH and Ma-Tsu Island hospital.

Videoconferencing in synchronous teleconsultations requires high video quality for diagnosis (Fig. 5). According to an experiment using different bandwidths for realtime ultrasound consultations, $768 \mathrm{~K}$ is a minimal requirement for diagnostic purposes (Fig. 6) [52]. In all of the systems half of the bandwidth is used for videoconferencing and the other half is used for digital information transmission applied in asynchronous consultation. The four vertical connections of the teleconsultation networks have become a regular service for rural areas provided by the government. Approximately 2000 consultations are made every year.

The horizontal connections among medical centers run less frequently, but in some special fields such as gastroenterology endoscopy, and rehabilitation less expensive ISDN lines provide occasional consultations and case discussion conferences.

\subsection{Promotion research stage}

\subsubsection{Family medicine tele-course CME}

This project intended to justify the effectiveness of the ISDN video-conferencing system in delivering lectures from medical centers to community hospitals. The Department of Family Medicine, National Taiwan University Hospital offered a series of telecourses for Provincial Taipei Hospital in

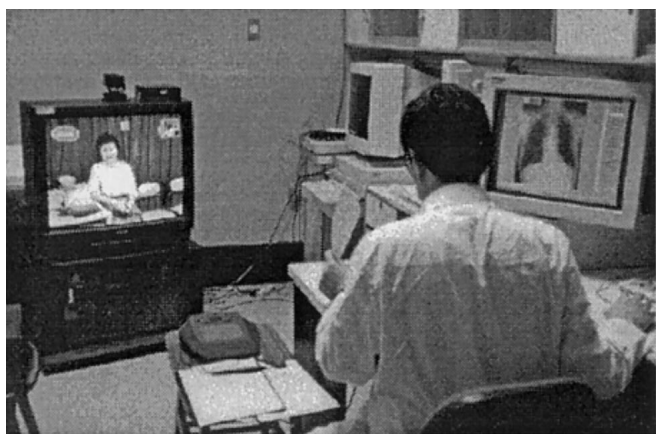

Fig. 5. Videoconference and teleradiology. 


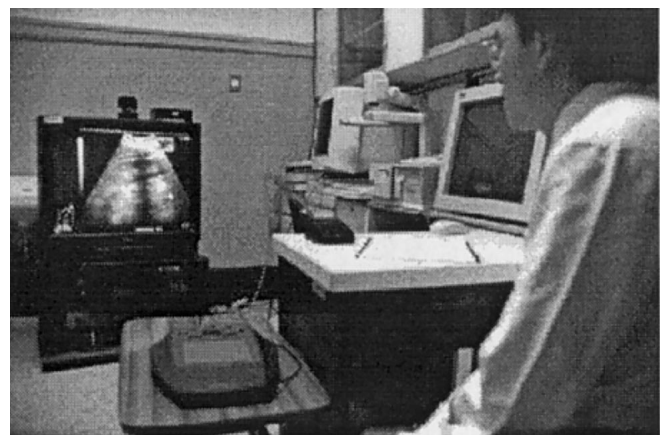

Fig. 6. Ultrasound consultation.

1997 [53]. A desktop video-conferencing system and $128 \mathrm{~K}$ ISDN were used for better cost-effectiveness. The quality of the ISDN video-conferencing system was appropriate for delivering tele-courses. The audio quality, especially echo canceling, was the most important factor affecting satisfaction with telecourses. There was no difference between the satisfaction with on-line slide scrolling controlled by the speaker and the off-line method controlled by the audience. There was also no difference in satisfaction between room-based and desktop video-conferencing systems.

\subsubsection{Multi-center palliative medicine teleconference}

Palliative medicine is a new medical profession in Taiwan, and if requires close and frequent cooperation among hospitals. This project evaluated the effectiveness of a distance education model used for palliative case conferences. Five medical centers joined this project including NTUH, NCKUH, VGHTPE, Buddhist Tsu-Chi General Hospital and Mackay Memorial Hospital. An ISDN network integrated synchronous and asynchronous distance education. A desktop video-conferencing system at each site is connected to an MCU for a monthly case conference (Fig. 7). An electronic white board and web pages are used for on line interaction. Each medical center takes turns presenting a case for discussion participants [54]. A structured questionnaire was used to evaluate satisfaction. An evaluation of 116 questionnaires showed that overall satisfaction with the audio, video and Participants were least satisfied with slide show was $94.0 \%, 93.1 \%$, and $86.7 \%$ respectively. Synchronization of the of speaker's lips and speech, smoothness of the motion pictures and the illumination/contrast/color of the slides. There was no significant difference in satisfaction between remote and local sites. Participants who were directly involved in the care of palliative cases were more satisfied with the conference. The reliability of ISDN and MCU at the initial stage was not satisfactory, but it became better afterwards. The quality of the video-conferencing system was acceptable. The web-base case library played an important role in this study (Fig. 8) [55]. However, the effectiveness of asynchronous distance education needs further study.

\subsubsection{Web-based CME network}

The principle aim of this project is the application of telecommunication techniques to decrease clinicians' effort and time in continuing medical education. NTUCM collaborated with the Formosan Medical
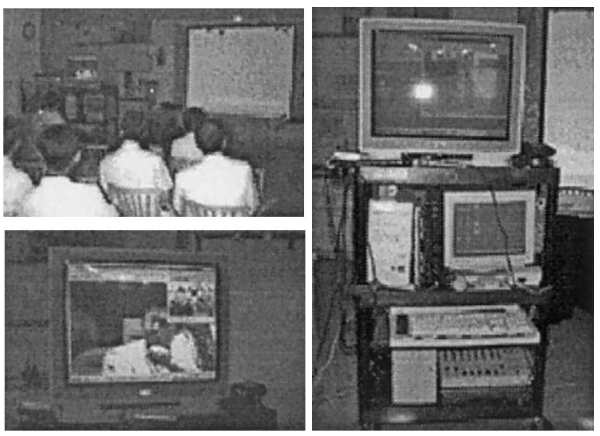

Fig. 7. Multi-center videoconference. 


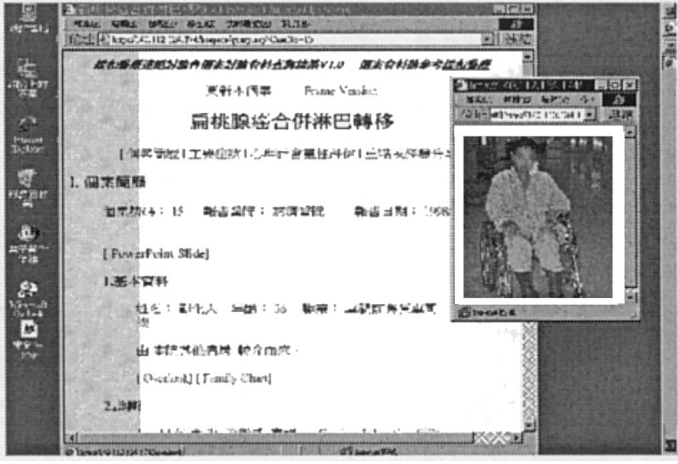

Fig. 8. Web-based multimedia case library.

Association and the Taiwan Association of Family Medicine to develop web-based CME applications. We started a Chinese full-text electronic journal the 'Formosan Journal of Medicine' with online CME credit (Fig. 9) [56]. For efficiency and easy management, the content of the web-based journal is stored in a multimedia database. Three user interfaces were designed for the database manager, the journal editor and the reader to control access privilege and security. Another application is a virtual classroom providing web-based distance learning courses with VOD and multimedia teaching materials (Fig. 10) [57]. Physicians may attend syn-

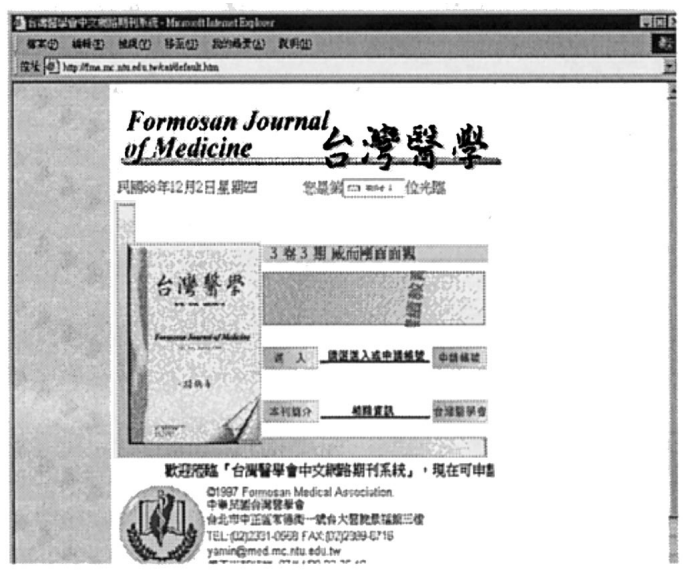

Fig. 9. Chinese full-text electronic journal.

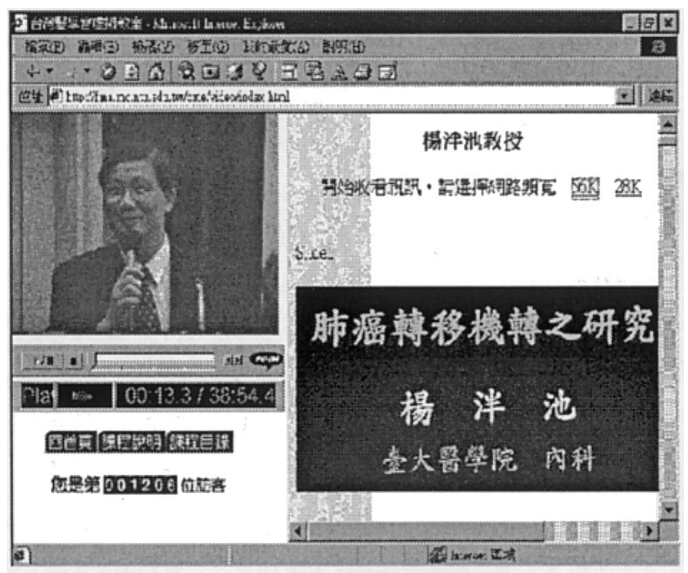

Fig. 10. Web-based video on demand (VOD).

chronous continuing medical education or asynchronous web-courses at home or at the work place. The Association of Family Medicine has modified the regulation for CME accreditation to adopt a variety of distant learning courses as a measure to obtain CME credits.

\section{Prospect}

With continuing advances in information technology, the applications of computers in medicine are increasing rapidly [58]. Modern information technology not only affects the delivery of healthcare [59], but also significantly influences the doctor-patient relationship. Technological developments in high bandwidth telecommunications systems and digitizing devices since the 1990s have led to a surge of interest in telemedicine. In recent years, the Internet, with its powerful penetration and scalability, has become an increasingly popular medical information resource and a new platform for telemedicine [60-62]. The impact of modern technology on the advancement of telemedicine in Taiwan started with the NII project, which uses net- 
works of different bandwidths for tele-consultation and distance education programs [63]. In 1998, National Taiwan University and Taipei Medical College in Taiwan, and the University of Pittsburgh and the University of Iowa in the USA began cooperation on a new Cyber Medical Center (CMC) project that integrates the technologies of multimedia, networking, database management, and the World Wide Web. The aim of the CMC is to create a multimedia network system for management of electronic patient records, teleconsultation, online continuing medical education, and information services on the web [64]. The progress of CMC at present includes a Taiwan mirror site of Virtual Hospital, a web-based multimedia database for medical information and patient records $[65,66]$, and promotion of several full-text electronic journals providing CME credits and VOD for archiving CME lectures. By the end of 1998, we had two international telemedicine trials through Next Generation Internet (NGI) including teleconsultation with the University of Iowa on high-speed CT for analysis of pulmonary function, and distance education with the University of Pittsburgh on high quality MPEG1 VOD for medical education. In the future, telemedicine systems in Taiwan are expected to combine the Internet and broadband CATV, ADSL, and DBS networking $[67,68]$ to connect clinics, hospitals, insurance organizations, and public health administrations [69,70]; and, finally, to extend to every household.

\section{Acknowledgements}

The authors wish to express their appreciation for the many research grants from the National Health Research Institute (DOH88HR-816), the Department of Health, the National Science Council (NSC-85-2511-S-002-
031, NSC-86-2511-S-002-007, NSC-87-2511S002-014) and the Ministry of Education, Taiwan.

\section{References}

[1] Directorate-General of Budget, Accounting and Statistics, Executive Yuan (DGBAS), Taiwan: National statistics of Taiwan, 1999, http:// www.stat.gov.tw/

[2] Health Care Financing Administration (HCFA): Community Hospital Statistics, 1999, http:// www.hcfa.gov/stats/indicatr/tables/t01.htm

[3] J.C. Hsu, Causes of failure to establish a referral system in National Health Insurance, Taiwan Med. J. 41 (1999) 246-247.

[4] Department of Health, Executive Yuan, Taiwan: Statistics of public health in Taiwan, 1998, http:// www.doh.gov.tw/lane/statist/87/

[5] J.W. Williamson, P.S. German, R. Weiss, et al., Health science information management and continuing education of physicians: a survey of US primary care practitioners and their opinion leaders, Ann. Intern. Med. 110 (1989) 151-160.

[6] P.G. Ramsey, J.D. Carline, T.S. Inui, et al., Changes over time in the knowledge base of practicing internists, J. Am. Med. Assoc. 266 (1991) 1103-1107.

[7] W.R. Hersh, D.H. Hickam, How well do physicians use electronic information retrieval systems? A framework for investigation and system review, J. Am. Med. Assoc. 280 (1998) 1347-1352.

[8] D.A. Davis, H.A. Thomson, A.D. Oxman, et al., Evidence for the effectiveness of CME. A review of 50 randomized controlled trials, J. Am. Med. Assoc. 268 (1992) 1111-1117.

[9] R.L. Bashshur, P.A. Armstrong, Telemedicine: a new mode for the delivery of health care, Inquiry 13 (1976) 233-244.

[10] R.L. Bashshur, On the definition and evaluation of telemedicine, Telemed. J. 1 (1995) 19-30.

[11] D.A. Perednia, A. Allen, Telemedicine technology and clinical applications, J. Am. Med. Assoc. 273 (1995) 483-488.

[12] J. Grigsby, J.H. Sanders, Telemedicine: where it is and where it's going, Ann. Intern. Med. 129 (1998) 123-127.

[13] H.S. Chen, F.R. Guo, The advancement and perspective of telemedicine in Taiwan, in: The humanities and science, Taipei, Taiwan. Proceedings 
of the Young Scholars Forum across the Taiwan Strait, 1999, pp. 329-351.

[14] K.C. Lun, The status of telemedicine in the Asia Pacific [Abstract], 1997 Medical Informatics Symposium in Taiwan, Taipei, Taiwan, 1997, p. 14.

[15] Department of Statistics, Ministry of the Interior, Executive Yuan, Taiwan: Statistics of Age Distribution in Taiwan, 1999, http://www.moi.gov.tw/ W3/stat/

[16] G.C. Doolittle, A. Yaezel, F. Otto, et al., Hospice care using home-based telemedicine systems, J. Telemed. Telecare 4 (1998) 58-59.

[17] G. Doolittle, A POTS-based tele-hospice project in Missouri, Telemed. Today 5 (1997) 18-19.

[18] S.W. Chisholm, M.A. Hahn, Emerging Veterans Health Administration geriatric and extended care initiatives, Geriatric Nurs. 16 (1995) 42-44.

[19] H.S. Lin, H.L. Chen, D.L. Liu et al., NetCare City: A Tele-visit System of Nursing Home at National Taipei College of Nursing, 1999, Medical Informatics Symposium in Taiwan, Taipei, Taiwan, 1999, p. 18.

[20] E.P. Hsu, National Information Infrastructure Development in Taiwan,1999, http:// www.nii.gov.tw/niieng/y1999/nii0909.htm

[21] Global Reach: Global Internet Statistics,1999, http://www.glreach.com/globstats/

[22] NII Steering Committee, Executive Yuan, Taiwan: Information and Telecommunication Statistics, 1999.

[23] Internet Software Consortium: Internet Domain Survey, 1999, http://www.isc.org/ds/WWW-9907/ report.html

[24] H.S. Chen, F.R. Guo, C.T. Liu et al., Telemedicine Project in Taiwan: Development and Prospect, Health Congress Asia 98, Singapore, 1998, pp. 4:1-19.

[25] L.S. Fu, Review of technology and barriers in telemedicine, J. China Assoc. Med. informatics 4 (1996) 88-102.

[26] H.S. Chen, F.R. Guo, J.H. Chen et al., Progress and Prospect of Telemedicine in Taiwan [Abstract], 1999 WONCA Asia Pacific Regional conference, Taipei Taiwan, 1999, p. 104.

[27] H.S. Chen, Information Systems in Primary Care in Taiwan [Abstrct], WONCA Asia Pacific Regional conference, 1999, Taipei Taiwan, 1999, p. 102.

[28] H.S. Chen, Distance education network in medical education, Formosan J. Med. 1 (1997) 607-612 [Chinese].
[29] H.S. Chen, Computer assisted learning system in medicine, Formosan J. Med. 1 (1997) 733-740 [Chinese].

[30] J.F. Chang, T.Y. Huang, A Preliminary Survey for NII Distance Education Experimental Project, Ministry of Education, Taiwan, 1995.

[31] H.S. Chen, C.T. Liu, F.R. Guo et al., Virtual Medical School: Computer Assisted Learning Network of Medical Education [Abstract], 1997 Medical Informatics Symposium in Taiwan, Taipei, Taiwan, 1997, p. 20.

[32] H.S. Chen, F.R. Guo, C.T. Liu, et al., Integrated medical informatics with small group teaching in medical education, Int. J. Med. Informatics 50 (1998) 59-68.

[33] C.H. Chien, WEBPES (web based pathology education system) in NCKUMC: Assisted Lecturing to Medical Students in Internet [Abstract], 1997 Medical Informatics Symposium in Taiwan, Taipei, Taiwan, 1997, p. 29.

[34] H.S. Chen, A.Y. Wang, C.C. Lin et al., A Clinical Case Study: Computer Assisted Distance Education System, 1998 Medical Informatics Symposium in Taiwan, Taipei, Taiwan, 1998, pp. 13-16 [in Chinese; English abstract].

[35] D.W. Lee, K.J. Yu, C.Y. Dai, Effectiveness Evaluation of Distance Education Experimental Project, Ministry of Education, Taiwan, 1996, pp. 114-120 [in Chinese].

[36] H.S. Chen, National Taiwan University distance education system: a pilot project, Distance Educ. 1 (1997) 11-14 [in Chinese].

[37] H.S. Chen, J.Y. Chen, F.R. Guo, et al., The effectiveness of broadband distance education system in medical general education, J. Med. Educ. 2 (1998) 145-155 [in Chinese; English abstract].

[38] F.R. Guo, H.S. Chen, F.C. Tsai, et al., The evaluation of an ISDN desktop distance education system, J. Med. Educ. 1 (1997) 55-68 [in Chinese; English abstract].

[39] I. Chang I, C.H. Chi, B. Tan et al., The Evaluation of Distance Learning on Medical Education: An Example of The 'First Aid' Course Among NCKU, CNCPS and CCMT, 1999 Medical Informatics Symposium in Taiwan, Taipei, Taiwan, 1999, pp. 84-89.

[40] W.W. Jiang, W. Chen, C.S. Lee, Establish a Classroom for Synchronized Distance Education in Nursing, 1999 Medical Informatics Symposium in Taiwan, Taipei, Taiwan, 1999, pp. 90-93.

[41] C.T. Liu, F.R. Guo, R.S. Chen, H.S. Chen, et al., Evaluation of an interactive teleconsultation system, Chin. J. Fam. Med. 7 (1997) 13-23. 
[42] H.J. Tschai, S.C. Wu, Quality Service Model of Medical Image in Broadband Data Network, 1998 Medical Informatics Symposium in Taiwan, Taipei, Taiwan, 1998, pp. 1-9 [in Chinese; English abstract].

[43] L. Liu, Y.C. Li, S. Pan, Internet/intranet-based picture archiving and communication systems, J. China Assoc. Med. Informatics 6 (1997) 1-10.

[44] H.J. Tschai, G.S. Yang, Integrating management of PACS, J. China Assoc. Med. Informatics 8 (1998) 86-97.

[45] C.T. Liu, C.C. Lin, R.S. Chen, et al., Design and evaluation of a telediagnosis system, J. Biomed. Eng. Appl. Basis Commun. 9 (1997) 125-133.

[46] C.C. Lin, J.R. Duann, C.T. Liu, H.S. Chen, J.L. $\mathrm{Su}$, J.H. Chen, A unified multimedia database system supporting tele-medicine, IEEE Trans. Infor. Technol. BioMed. 2 (1998) (1998) 183-192.

[47] C.T. Liu, A Web-based Telemedicine System [Abstract], 1997 Medical Informatics Symposium in Taiwan, Taipei, Taiwan, 1997, p. 33.

[48] H.S. Chen, C.C. Lin, J.H. Chen, The Development and Implementation of Medical Information System for Tele-medicine in NTUH, IEEE EMBS 98 Workshop of Advance in Telemedicine, HongKong, 1998.

[49] R.S. Chen, S.K. Chen, Teledentistry between NTHU and Ching-Shan group Health Center - A Feasibility Study, 1999 Medical Informatics Symposium in Taiwan, Taipei, Taiwan, 1999, p. 28.

[50] S.K. Chen, R.S. Chen, A DICOM Teleradiology System in Dental Care, 1999 Medical Informatics Symposium in Taiwan, Taipei, Taiwan, 1999, p. 53.

[51] I. Chang, W.P. Wu, C.H. Chi, Telemedicine in Taiwan: the evaluation of a telemedicine pilot project in Peng-Hu Islands, J. China Assoc. Med. Informatics 4 (1996) 31-42.

[52] Y.C. Chang, H.S. Chen, C.C. Lin et al., Current Development in Teleradiology and Teleconsultation of the NTU Telemedicine Network [Abstract], 1999 NSC-NSF Joint Workshop on NGI Applications, Hsinchu, Taiwan, 1999, p. 31.

[53] F.R. Guo, H.S. Chen, C.T. Liu et al., Delivering Tele-courses from a Medical Center to a Community Hospital through ISDN Video-Conferencing System, 1997 Medical Informatics Symposium in Taiwan, Taipei, Taiwan, 1997, p. 28.

[54] F.R. Guo, M.H. Lin, L.A. Shue et al., Multi-Center Palliative Case Conferences: The Experience of Three Hospitals in Taiwan [Abstract], 1999 WONCA Asia Pacific Regional conference, Taipei Taiwan, 1999, p. 105.
[55] W.L. Kao, H.S. Chen, F.R. Guo et al., A WebBased Palliative Medicine Database for Case Teleconference, 1999 Medical Informatics Symposium in Taiwan, Taipei, Taiwan, 1999, p. 23 [in Chinese].

[56] Y.M. Ouh, H.S. Chen, F.R. Guo et al., A WebBased Full-Text Electronic Medical Journal, 1999 Medical Informatics Symposium in Taiwan, Taipei, Taiwan, 1999, p. 24 [in Chinese].

[57] L.R. Chen, F.R. Guo, H.S. Chen et al., A Video On Demand (VOD) for Continuing Medical Education (CME), 1999 Medical Informatics Symposium in Taiwan, Taipei, Taiwan, 1999, p. 94[in Chinese].

[58] J.H. Lin, H.S. Chen, R.G. Lee et al., New Method for Medical Data Analysis, 1999 Medical Informatics Symposium in Taiwan, Taipei, Taiwan, 1999, p. 12.

[59] C.M. Huang, C.H. Wen, H.G. Hwang, An Extranet application for referrals: Tai-Chung Veteran General Hospital case, J. China Assoc. Med. Informatics 9 (1999) 19-38 [in Chinese; English abstract].

[60] Y.C. Li, L. Liu, P.L. Chang, Impact of Internet on medical information distribution, J. China Assoc. Med. Informatics 4 (1996) 78-87.

[61] S.F. Tseng, L.M. Chang, The content of medical information websites and its usage, J. China Assoc. Med. Informatics 6 (1997) 54-66 [in Chinese; English abstract].

[62] S.F. Tseng, L.M. Chang, C.H. Chang et al., The Impact of Health Consulting Internet on DoctorPatient Relationship, 1999 Medical Informatics Symposium in Taiwan, Taipei, Taiwan, 1999, pp. 15-21 [in Chinese; English abstract].

[63] H.S. Chen, F.R. Guo, C.C. Lin et al., Impact of Modern Information Technology on Telemedicine in Taiwan, 1999 Medical Informatics Symposium in Taiwan, Taipei, Taiwan, 1999, pp. 68-72 [in Chinese].

[64] H.S. Chen, Cyber Medical Center: A Virtual Hospital in Taiwan [Abstract], 1999 NSC-NSF Joint Workshop on NGI Applications. Hsinchu, Taiwan 1999, p. 31.

[65] W.H. Hsu, C.C. Lin, H.S. Chen et al., Web-Based Network Clinic System, 1998 Medical Informatics Symposium in Taiwan, Taipei, Taiwan, 1998, pp. 17-23 [in Chinese; English abstract].

[66] C.T. Liu, S.K. Hou Chang et al., An XML-based approach to exchange patient records among hospitals [Abstract], 1998 Medical Informatics Symposium in Taiwan, Taipei, Taiwan, 1998, p. 54. 
[67] R.G. Lee, H.S. Chen, K.C. Chang et al., Home Tele-care Service over Digital Broadband Cable Television Plants, 1999 Medical Informatics Symposium in Taiwan, Taipei, Taiwan, 1999, p. 81.

[68] R.G. Lee, H.S. Chen, C.C. Lin et al., Home Tele-care System Using Cable Television Plants - An Experimental Trial, IEEE Trans Infor Technol BioMed, 1999 (in print).
[69] H.J. Tschai, C.C. Lin, G.S. Yang, Medical Information Exchange Model Using WWW Technology, 1999 Medical Informatics Symposium in Taiwan, Taipei, Taiwan, 1999, pp. 61-67 [in Chinese; English abstract].

[70] W.S. Jen, Y.C. Li, D.D. Tang, et al., Building a prototype of medical information exchange center, J. China Assoc. Med. Informatics 6 (1997) 54-66 [in Chinese; English abstract]. 